\title{
Study on Countermeasures of coordinated development of new Urbanization and Agricultural modernization of Jilin province under the perspective of Financial support
}

\author{
Jinjie Gao \\ Department of economic management, Changchun University of Science and Technology, \\ Changchun 310020, China
}

13251803199@163.com

Keywords: New urbanization; Agricultural modernization; financial support.

\begin{abstract}
This article contains the concept of coordinated development of new urbanization and agriculture modernization and the theory of financial development, shows the actuality of the coordinated development of Jilin Province new urbanization and agriculture modernization under the perspective of financial support, and points out problems blocking balanced development of new urbanization and agriculture modernization in Jilin Province as follows: the infrastructure construction of new urbanization financing channel is single; SMEs financing is difficult; financial supply of agricultural modernization is scarce. The goal of balanced development of new urbanization and agriculture modernization in Jilin province is to take a road of urbanization. Based on this, the measures are came up with in Jilin Province as following: develop various forms of infrastructure construction financing channels; and remove small and medium-sized enterprise financing difficulties; and Strengthen the financial support of agricultural modernization.
\end{abstract}

\section{The concept of coordinated development of new urbanization and agriculture} modernization and the theory of financial development

The coordinated development of new urbanization and agriculture modernization in Jilin Province means that they reinforce each other, realize the virtuous cycle development commonly. The new urbanization refers to the process that a mass of rural population divert into the towns or cities, the second and third industry ceaselessly assemble to the town, so as to increase the number of cities or towns and extend urban scale. The new urbanization emphasis on the people-oriented, and realize person's all-sided development. The goal of new urbanization is that enhance the level of public service quality, and improve the infrastructure construction and residents' way of life.

The agriculture modernization means that the process traditional agriculture transforming into modern agriculture. In this process, a great deal of modern industrial technology is utilized in the agriculture activities. The aim of agriculture modernization is that increase farmers' income and living standards, which makes the gap between urban and rural areas.

The theory of financial development is about the relationship between economic growth and the financial development. It mainly study on the role of financial system which including the financial intermediary and financial markets in the economic development. And it research how to establish an effective financial system and financial policy combination with maximizing economic growth and how to reasonable use of financial resources in order to realize the sustainable development of the financial and eventually realize the sustainable development of the economy.

\section{Financial support under the perspective of Jilin province urbanization and agricultural modernization the coordinated development of actuality}

Jilin is a big province of agriculture. In recent years the balanced development of new urbanization and agriculture modernization has made great achievement. In the process of coordinating the development of the inevitable birth of a large number of diverse financing needs, has raised new requirement on financial sector. Now the actuality of new urbanization and agriculture modernization under the perspective of financial support is followed in Jilin province. 


\subsection{Financial support for the construction of towns in Jilin Province}

Jilin Province the financial support for the construction of towns constantly enhanced. As we can see from the table 1, during 2003 to 2013, Jilin Province fixed assets investment funds mainly from domestic loans and self-financing \& other investments. And the proportion of them is continuously incremental. The fiscal expenditure and utilization of foreign capital, is relatively small. In 2013, for example, the budget of about 29.84 billion RMB, while domestic loans and self-financing and other investment respectively reached 58.72 billion RMB, 906.58 billion RMB, respectively, 1.97 times and 30.38 times the budget. And the utilization of foreign capital is trivial, the proportion of it is 2.79 billion RMB in 2013. This fully shows that in fixed asset investment, financial support inhibit the development of new urbanization. Although the financial support has played a role, yet support still to be strengthened. Financial support play an irreplaceable role in the process of urbanization.

Table 1 Funding sources of investment in fixed assets (unit:billion yuan)

\begin{tabular}{|c|c|c|c|c|}
\hline Year & $\begin{array}{c}\text { Fiscal } \\
\text { expenditure }\end{array}$ & $\begin{array}{c}\text { Domestic } \\
\text { loans }\end{array}$ & $\begin{array}{c}\text { Utilization of foreign } \\
\text { capital }\end{array}$ & $\begin{array}{c}\text { Self-financing \& other } \\
\text { investments }\end{array}$ \\
\hline 2003 & 4.09 & 11.25 & 1.09 & 80.48 \\
\hline 2004 & 5.11 & 13.44 & 2.05 & 96.56 \\
\hline 2005 & 10.79 & 23.44 & 3.62 & 142.40 \\
\hline 2006 & 8.69 & 27.51 & 6.24 & 237.99 \\
\hline 2007 & 11.74 & 30.16 & 5.26 & 353.15 \\
\hline 2008 & 17.12 & 29.99 & 7.74 & 505.96 \\
\hline 2009 & 27.88 & 47.85 & 4.94 & 645.29 \\
\hline 2010 & 42.11 & 54.36 & 5.83 & 859.89 \\
\hline 2011 & 23.44 & 46.17 & 6.68 & 667.88 \\
\hline 2012 & 25.65 & 43.69 & 5.54 & 876.29 \\
\hline 2013 & 29.84 & 58.72 & 2.79 & 906.58 \\
\hline
\end{tabular}

The date source: Jilin province in 2005-2014 statistical yearbook

\subsection{Jilin financial support in the development of new urbanization industrial restructuring}

The new urbanization inevitably leads to industrial structure adjustment. Over the past decade, Jilin three main industries' proportion of GDP undergone significant changes, the industrial structure tend to be more efficient and rationalized. This trend contains that the first industrial percentage declined year by year, the proportion of secondary industry is still high, compared with them, the third industrial percentage tend to be stable. The specific date in the following table: the first industry to GDP ratio declined from $19.3 \%$ in 2003 to $11.3 \%$ in 2013, the second and third industry share of GDP rose from $45.3 \%$ and $35.4 \%$ in 2003 , respectively, to $52.8 \%$ and $35.9 \%$ in 2013 . Industrial structure adjustment accelerated urbanization. However, the optimization and upgrading of industrial structure is not a bunch of things around, which requires long-term financial support.

\subsection{Current Situation in Jilin Province Rural Financial Development}

Jilin as a big agricultural province, is China's important commodity grain production base. Insurance company as a crucial part of the financial industry, play an important role in support of agriculture development. Jilin agricultural insurance premiums account for total premium income is soaring, reaching the highest point of $4.33 \%$ in 2007. But since 2011, the latest three years the proportion of increase year after year has yet to catch up with the highest point, indicating that the insurance company support for the development of agriculture is not enough nearly three years. So insurance companies need to continue to increase support for agriculture, thus contributing to agricultural development. And efficient development of agriculture in turn will promote the development of the insurance industry. 
Table 2 Each industry in Jilin province as a share of GDP (\%)

\begin{tabular}{|c|c|c|c|}
\hline Year & The first industry of GDP & The second industry of GDP & The third industry GDP \\
\hline 2003 & 19.3 & 45.3 & 35.4 \\
\hline 2004 & 18.2 & 42.6 & 39.2 \\
\hline 2005 & 17.3 & 43.7 & 39.1 \\
\hline 2006 & 15.7 & 44.8 & 39.5 \\
\hline 2007 & 14.8 & 46.8 & 38.3 \\
\hline 2008 & 14.3 & 47.7 & 38.0 \\
\hline 2009 & 13.5 & 48.7 & 37.9 \\
\hline 2010 & 12.1 & 52.0 & 35.9 \\
\hline 2011 & 12.1 & 53.1 & 34.8 \\
\hline 2012 & 11.8 & 53.4 & 34.8 \\
\hline 2013 & 11.3 & 52.8 & 35.9 \\
\hline
\end{tabular}

The date source: Jilin province statistical yearbook-2005 to 2014

\section{The main problems blocking coordinated development of new urbanization and agricultural modernization under the perspective of financial support in Jilin Province}

Since the 18th CPC National Congress, the economic development of Jilin Province has obtained a great accomplishment. The process of new urbanization and agricultural modernization has been boosted sequentially. Meanwhile it also faces great challenges and problems as follows: the financing channel in infrastructure construction of new urbanization in is single; SME's financing is difficult; financing supply agricultural modernization is shortage.

\subsection{The financing channel in infrastructure construction of new urbanization in Jilin Province is single}

Infrastructure construction is the important index to measure the development of a region urbanization. Jilin province in accelerating the pace of the construction of the new urbanization, the role of the infrastructure is more and more obvious. Infrastructure-public goods-determines its financing channel mainly comes from fiscal spending. But in recent years, fiscal deficits in Jilin Province, in 2013, for example, expenditure is 2.7 times as much revenue, which can be seen financial support urbanization slightly inadequate infrastructure construction. Fiscal deficits will not be solved in a period of time. So infrastructure funding needs different approach. The bank will become the important source of funds to support infrastructure construction. However, due to the infrastructure is non-exclusive and non-competitive, and infrastructure construction cycle is long, income is relatively fixed, leads to it is inconsistent with the bank's profit target.

\subsection{Jilin SMEs' financing is difficult}

The development of small and medium-sized enterprises (smes) continues to play an important role in the urbanization process in China. Financing SMEs in Jilin is mainly from bank loans and nonfinancial institutions of equity financing and debt financing. SMEs' financing highly relied on commercial bank loans, but by its lower credit rating and the lack of collateral, it increased SMEs' difficulty in bank loans. Equity financing is also not optimistic. Small board and GEM are offering financing for SMEs in the arena, and are subject to stringent listing requirements and regulatory restrictions. For example, in November 2014, Jilin Province in the small board, the GEM listed companies were 6 home and one, two plates do not add up to the 10 listed companies, it is difficult to provide adequate funding for SMEs.

\subsection{Jilin Agricultural Modernization financial supply is shortage}

With the advancement of Jilin agricultural modernization, the demand of money becomes also more and more strong. It mainly includes following aspects: on the one hand, the infrastructure needs fund. Infrastructure construction needs a lot of money, local governments cannot afford to rural areas of the construction of infrastructure, so they must raise fund through the financial system. On the 
other hand, agricultural industrialization also needs fund. Agricultural industrialization involving the agricultural production, processing, transportation, sales, and other links, it needs agricultural insurance to support agricultural industrialization. Currently, Jilin Province has been basically established five one of the rural financial system which contains commercial finance, policy finance, agricultural insurance, cooperative finance and private capital. But the proportion of various financial institutions is not perfect and functions is serious deficiencies, resulting in poor rural resource allocation efficiency is low. It is difficult to provide agricultural modernization financial support, and the limited local financial funds cannot meet the capital needs of agricultural modernization.

\section{The countermeasures for the coordinated development of new urbanization and agricultural modernization under the perspective of financial support in Jilin Province}

In order to solve the current highlighted problems blocking the coordinated development of new urbanization and agricultural modernization under the perspective of financial support in Jilin Province, and achieve benign interaction and synchronized advancement of new urbanization and agricultural modernization. There are many ways to improve the main problems, as follows: Develop various forms of infrastructure construction financing channels; Remove small and medium-sized enterprise financing difficulties; strengthen the financial support of agricultural modernization.

\subsection{Develop various forms of infrastructure construction financing channels}

According to yhe problem of Jilin province infrastructure financing channels is single, you can take the following measures to make up for it. Firstly, Jilin province can promote to BOT (build operation - transfer mode), the PPP (public- private partnerships), ABS (asset \& bond securitization), and other infrastructure construction financing for the project financing model. Secondly, Jilin province can try to issue the government credit for guarantee of municipal construction bonds from the public to raise capital construction of infrastructure. Thirdly, bank through the development of urban construction of credit products, fully mobilize social idle funds to support urban infrastructure construction.

Commercial banks shall actively on the premise of risk control and bold innovation, seek commercial Banks to support the new mode of the infrastructure construction of urbanization.

\subsection{Remove small and medium-sized enterprise financing difficulties}

The problem of Jilin province in view of the small and medium-sized enterprises financing is difficult, the government can take the following measures to improve. On the one hand, by loosening of the examination and regulation constraints at village banks, petty loan companies, leasing companies, make them provide the necessary funding for SMEs. On the other hand, the government can encourage commercial banks provide money to small and medium-sized enterprises through tax breaks, subsidies and other concessional measures. And finally, by lowering the threshold of the stock market, many companies jointly issued a set of bonds, encouraging SMEs in the stock and bond market to directly raise money.

\subsection{Strengthening the financial support of agricultural modernization}

The problem of Jilin province Agricultural Modernization for financial supply is shortage, the following measures should be taken to strengthen. First of all, giving full play to the government's macro-control functions, strengthen financial support for the modernization of agriculture policy guidance, while enhancing the financial allocations and subsidies. Then Jilin province should build a corresponds to the agriculture modernization commercial banking system. Through the reform and innovation of financial system, Jilin province promote the city capital flow to the rural areas, rural rich sources of funds to provide financial support for the modernization of agriculture. Finally, governments accelerate agricultural insurance services and premium of local fiscal subsidies.Meanwhile governments should mobilize commercial insurance companies to actively carry out agricultural insurance business and increase insurance products to enhance farmers' participation in agricultural insurance rates. 


\section{Conclusion}

Based on the financial support of the new urbanization in Jilin Province and the coordinated development of modern agricultural research, we can see the current Jilin Province is still insufficient in terms of financial support. But through the implementation of appropriate policies, author believe that the future of the new urbanization in Jilin Province and agricultural modernization development must be coordinated well.

\section{References:}

[1] Kyung-Hwan Kim Housing Finance and Urban Infrastructure Finance. Urban Studies. Vol. 34(1997) No. 10, p. 159-163.

[2] Jones, Donald W. Urbanization and Energy Use in Economic Development. The Energy Journal. Vol. 10 (2002) No.4, p.29-45.

[3] Wenxin Chen, Yuxia Zhang. Try to talk about financial support in the process of the urbanization [J]. Journal of commercial age, 2013 (2): 69-71. (in Chinese)

[4] Tingting $\mathrm{Xu}$. Financial support in promoting urbanization process [J]. Operation and management, 2013 (4): 18-21. (in Chinese)

[5] Stopher, Peter R. Intercity Passenger Forecasting: the Use of Current Travel Forecasting Procedures [M]; Transportation Research Forum; 1993

[6] Iwami, Toru. Economic development and environment in Southeast Asia; an introductory note. International Journal of Social Economics. Vol. 28 (2008) No. 8, p.605-622 